\title{
Isoprenoid biosynthesis in the erythrocytic stages of Plasmodium falciparum
}

\author{
Fabiana Morandi Jordão, Emília Akemi Kimura, Alejandro Miguel Katzin/+ \\ Departamento de Parasitologia, Instituto de Ciências Biomédicas, Universidade de São Paulo, São Paulo, SP, Brasil
}

The development of new drugs is one strategy for malaria control. Biochemical pathways localised in the apicoplast of the parasite, such as the synthesis of isoprenic precursors, are excellent targets because they are different or absent in the human host. Isoprenoids are a large and highly diverse group of natural products with many functions and their synthesis is essential for the parasite's survival. During the last few years, the genes, enzymes, intermediates and mechanisms of this biosynthetic route have been elucidated. In this review, we comment on some aspects of the methylerythritol phosphate pathway and discuss the presence of diverse isoprenic products such as dolichol, ubiquinone, carotenoids, menaquinone and isoprenylated proteins, which are biosynthesised during the intraerythrocytic stages of Plasmodium falciparum.

Key words: malaria - Plasmodium falciparum - isoprenoids - methylerythritol phosphate (MEP) pathway

Malaria is one of the most important tropical parasitic diseases in humans, causing great morbidity and mortality in tropical regions with 300-500 million clinical cases and approximately one million deaths per year (WHO 2010). Human malaria is caused by five species of the Plasmodium parasites, namely Plasmodium falciparum, Plasmodium vivax, Plasmodium ovale, Plasmodium malariae and Plasmodium knowlesi (Cox-Singh \& Singh 2008). P. falciparum is responsible for the vast majority of malaria-related deaths (Snow et al. 2005). The global expansion of the disease has been attributed mainly to the failure of vector control programs, the absence of a vaccine and the increase in parasite resistance to drugs commonly used for therapy. As a result, the discovery and development of new and effective antimalarial agents is imperative. This aim can be achieved in three ways: (i) by focusing on previously validated parasite targets to generate new drug candidates, (ii) by identifying new potential parasite targets for malaria chemotherapy (Ridley 2002) or (iii) by performing highthroughput testing of drug libraries (Guiguemde et al. 2010). With many malaria parasite genome-sequencing projects now complete, efforts are being directed towards a better understanding of gene functions and the discovery of new drug targets (Gardner et al. 2002).

The phylum Apicomplexa harbours a relict plastid known as the apicoplast (McFadden et al. 1996); its discovery brought about an exciting new prospect for drug development against $P$. falciparum (Jomaa et al. 1999, Lim \& McFadden 2010). The apicoplast possesses four

Financial support: CNPq, FAPESP

FMJ is the recipient of a post-graduate fellowship from CNPq.

+ Corresponding author: amkatzin@icb.usp.br

Received 14 April 2011

Accepted 15 June 2011 membranes; therefore, it is hypothesised to be the result of a secondary endosymbiosis, which means that, at some point, the parasite engulfed another eukaryote that contained a plastid obtained by primary endosymbiosis of a cyanobacterium-like prokaryote (Funes et al. 2002, Moore et al. 2008). The apicoplast genome is clearly related to the plastid genome of plants and algae but has a greatly reduced sequence complexity and lacks the genes that encode proteins involved in photosynthesis. Because the structure of the apicoplast was retained in the parasite, it is thought to have an important function for the parasite's survival (Sullivan et al. 2000). A predicted apicoplast proteome has been assembled and putative pathways for the biosynthesis of fatty acids, isoprenoids, iron-sulphur clusters and haem have been mapped to the apicoplast. These metabolic pathways are distinct from the pathways found in the mammalian host, although which of these pathways make the apicoplast indispensable remains to be elucidated (Ralph et al. 2004).

Isoprenoids - With more than 23,000 primary and secondary metabolites, isoprenoids form the most diverse and abundant group of organic compounds in nature. They are derived from branched C5 isoprenoid units. The number of repetitions of this motif, cyclisation reactions, rearrangements and further oxidation of the carbon skeleton are responsible for the enormous structural diversity (Connolly \& Hill 1992). Many types of isoprenoids (steroids, cholesterol, retinoids, carotenoids, ubiquinones and prenyl groups bound to proteins) are essential components of the cellular machinery that are found in all organisms. They participate in a variety of biological processes: (i) carotenoids, chlorophyll and plastoquinone are essential constituents of the photosynthetic apparatus; (ii) ubiquinone, menaquinone (MQ) and plastoquinone are employed as electron carriers required for the mitochondrial respiratory chain; (iii) prenylated proteins, including Ras and Rho GTPases, function as signal transducers; (iv) dolichols participate in the post-translational modification of proteins, an event that is involved in tumour cell 
growth and differentiation and cellular signalling (Wang \& Ohnuma 1999); (v) phosphorylated dolichols have a role as carriers of oligosaccharides in the biosynthesis of glycoproteins and glycosylphosphatidyl inositol anchors (Burda \& Aebi 1999, Spiro 2002).

Isoprenoids vary greatly in size but are all synthesised from a common building block, the isoprene unit isopentenyl diphosphate (IPP) and its isomer dimethylallyl diphosphate (DMAPP). Two distinct and independent pathways exist that biosynthesise IPP: the classical mevalonate pathway and a mevalonate-independent methylerythritol phosphate (MEP) pathway.

The mevalonate pathway - Bloch (1958) and Lynen (1958) first described the mevalonate pathway in animals and yeast revised by Spurgeon and Porter (1981). For several decades, the mevalonate pathway was considered the only biosynthetic route leading to IPP and DMAPP. This pathway uses seven enzymes to supply the precursors in most eukaryotes (all mammals) and in archae bacteria, eubacteria, algae (except chlorophytes), higher plants, bryophytes and some protozoa such as Trypanosoma and Leishmania (Goldstein \& Brown 1990). This pathway starts with a reaction catalysed by a thiolase that produces acetoacetyl-CoA from two molecules of acetyl-CoA. A third acetyl-CoA is then condensed with acetoacetyl-CoA to form 3-hydroxy-3methylglutaryl-CoA (HMG-CoA) by HMG-CoA synthase. The NADPH-dependent HMG-CoA reductase then converts the CoA-bound compound to mevalonic acid (MVA). Next, MVA is sequentially phosphorylated by the mevalonate and diphosphomevalonate kinases to form MVA-5-diphosphate. This diphosphate is subsequently decarboxylated by mevalonate diphosphate decarboxylase to yield a pool of IPP, which is then converted to DMAPP by an IPP isomerase. The enzymes of the mevalonate pathway have been studied from a number of organisms, including humans. HMG-CoA reductase, the best-characterised and rate-limiting enzyme in the pathway, is the target of the statin class of cholesterollowering drugs (Alberts et al. 1980). Whereas the mevalonate pathway in bacteria was previously thought to be due to horizontal gene transfer from other domains, Lombard and Moreira (2011) demonstrated using phylogenetic analyses that the mevalonate pathway is likely ancestral not only in archaea and eukaryotes but also in bacteria. The authors concluded that the mevalonate pathway is likely an ancestral metabolic route in all three domains of life and was probably present in the last common ancestor of all organisms.

The MEP pathway - The MEP pathway was first described in eubacteria (Rohmer et al. 1993) followed by several photosynthetic organisms such as cyanobacteria (Cvejic \& Rohmer 2000), algae (Disch et al. 1998) and higher plants (Rohmer 1999). Later, it was described in apicomplexan parasites (Jomaa et al. 1999) and Mycobacterium tuberculosis (Bailey et al. 2002). It was also found in several pathogenic eubacteria but not in animals or archae bacteria (Lichtenthaler 2000). The initial step, catalysed by 1-deoxy-D-xylulose-5-phosphate (DOXP) synthase, is the formation of DOXP by the condensa- tion of pyruvate and glyceraldehyde-3-phosphate. The $d x p$ gene encoding this enzyme was first cloned from Escherichia coli (Lois et al. 1998). This key enzyme of the pathway requires thiamine diphosphate and divalent cations such as $\mathrm{Mg}^{2+}$ or $\mathrm{Mn}^{2+}$ for its activity. The enzyme DOXP reductoisomerase catalyses the rearrangement and subsequent reduction of DOXP to MEP. The activity of this enzyme is inhibited by fosmidomycin (Kuzuyama et al. 1998). MEP is then converted to 4-(cytidine-5diphospho)-2- $C$-methyl-D-erythritol (CDP-ME) in a cytosine triphosphate-dependent reaction by the isp $D$ gene product CDP-ME synthase. The next step is catalysed by the enzyme CDP-ME kinase and leads to the phosphorylation of CDP-ME. The product of this reaction, 4-(cytidine-5-diphospho)-2- $C$-methyl-D-erythritol-2phosphate (CDP-MEP-2P), is subsequently converted to 2-C-methyl-D-erythritol-2,4-cyclodiphosphate (ME$2,4-\mathrm{cPP}$ ) by the enzyme 2- $C$-methyl-D-erythritol 2,4 cyclodiphosphate synthase. IPP and DMAPP are synthesised through independent routes in the last steps of the MEP pathway (Lichtenthaler 2000). Additionally, the MEP pathway produces the precursor (DOXP) for the synthesis of the essential cofactors thiamine diphosphate and pyridoxal phosphate (Sprenger et al. 1997).

In the following section, we address the recent advances that were made by our group regarding the synthesis of downstream products of the MEP pathway in P. falciparum and the exploitation of these pathways as potential novel drug targets (Figure).

MEP pathway in P. falciparum - Various attempts to provide evidence for the existence of the mevalonate pathway in Plasmodium have led to ambiguous results. To characterise the presence of the mevalonate pathway, $\left[{ }^{3} \mathrm{H}\right]$ mevalonolactone or $(\mathrm{RS})-\left[5-{ }^{3} \mathrm{H}\right]$-mevalonate is commonly used to perform metabolic labelling (Goldstein \& Brown 1990). Unfortunately, all efforts to label isoprenoid constituents with these precursors in P. falciparum were unsuccessful. However, upon incubation of extracts from P. falciparum infected red blood cells with $\left[{ }^{14} \mathrm{C}\right]$ mevalonate, Mbaya et al. (1990) identified farnesyl pyrophosphate. Metabolic labelling of in vitro cultured parasites using $\left[{ }^{3} \mathrm{H}\right]$ mevalonolactone was performed to analyse dolichols and ubiquinones, but no products were identified (AM Katzin et al., unpublished observations). Inhibitors (lovastatin and simvastatin) of HMG-CoA reductase interfered with the in vitro development of $P$. falciparum, but only at high, pharmacologically irrelevant, concentrations (Grellier et al. 1994). Accordingly, no HMG-CoA reductase activity was detectable above background levels in extracts from P. falciparum and $P$. knowlesi (Vial et al. 1984).

Clastre et al. (2007) demonstrated that the MEP pathway was also active in other apicomplexan parasites, namely Eimeria tenella and Toxoplasma gondii. Additionally, transcription profiles confirmed that MEP pathway-related genes were transcribed in these parasites. Intriguingly, BLAST analysis showed that Cryptosporidium parvum and Cryptosporidium hominis lack both the MVA and MEP pathways. However, these species contain orthologs of prenyltransferases, suggesting that isoprenoid precursors perhaps may be acquired from the host. 
In Plasmodium, the apicoplast is the only site of isoprenoid precursor synthesis. Jomaa et al. (1999) demonstrated that a recombinant $P$. falciparum DOXP reductoisomerase, which converts DOXP to MEP, was enzymatically active and could be inhibited by fosmidomycin. The authors also demonstrated that fosmidomycin and its derivative FR900098 are able to inhibit the growth of $P$. falciparum in culture and suppress the in vitro growth of multidrug-resistant $P$. falciparum strains. Moreover, mice infected with the rodent malaria parasite Plasmodium vinckei were cured after treatment with fosmidomycin. However, FR900098 was found to be twice as effective as fosmidomycin. In the same work, the authors showed that an amino-terminal signal sequence in DOXP reductoisomerase targeted the enzyme to the apicoplast. In addition, DOXP reductoisomerase activity could be detected in crude and partially purified protein extracts from $P$. falciparum using a sensitive functional assay (Wiesner et al. 2000).

Recently, it was demonstrated that fosmidomycin directly inhibits its known target, DOXP reductoisomerase, and indirectly acts upon cells to inhibit a second target, the downstream enzyme MEP cytidyltransferase (Zhang et al. 2011). Umeda et al. (2010) obtained crystallised DOXP reductoisomerase from $P$. falciparum and preliminary Xray crystallographic and structural analyses by molecular replacement are in progress. Rohdich et al. (2001) characterised the recombinant enzyme 2-C-methyl-D-erythritol 2,4-cyclodiphosphate synthase in P. falciparum. Finally, Ralph et al. (2004) suggested the presence of several MEP pathway-related genes in $P$. falciparum, all of which possess apicoplast-targeting sequences, indicating that the DOXP pathway is localised in the apicoplast.

Cassera et al. (2004) showed by metabolic labelling with $\left[1-{ }^{14} \mathrm{C}\right]$ acetate, D-[U- $\left.{ }^{14} \mathrm{C}\right]$ glucose and $\left[2-{ }^{14} \mathrm{C}\right] \mathrm{DOXP}$ that the MEP pathway is functionally active in the intraerythrocytic stages of $P$. falciparum. This group identified all but one of the intermediates of the MEP pathway using high-performance liquid chromatography and mass spectrometric analyses. The identified intermediates were DOXP, MEP, CDP-ME, CDP-MEP-2P and ME2,4-cPP (Figure). The effect of fosmidomycin on levels of the MEP pathway intermediates was found to be the most prominent in ring stages and only minor inhibitory effects were observed in the trophozoite and schizont stages, reflecting differences in the drug sensitivity of the parasite blood forms. Cassera et al. (2004) also showed that the MEP pathway provides precursors for the synthesis of ubiquinone and dolichol. This result was demonstrated by the decrease in the ubiquinone and dolichol content in fosmidomycin-treated parasites. Because fosmidomycin inhibits the DOXP reductoisomerase and kills malaria parasites, the biosynthesis of isoprenoids has been presumed to be essential in Plasmodium.

Interestingly, and similar to effects observed for the inhibition of plasmodial dihydrofolate reductase (Zhang \& Rathod 2002), no alteration in the transcription of MEP pathway-related genes was found (Cassera et al. 2007), suggesting that there is no feedback control of transcription exerted by metabolites of the MEP path- way as is often found in other organisms. Surprisingly, fosmidomycin had only a small effect on the growth of either E. tenella or T. gondii in vitro, even at higher concentrations, suggesting that the drug either is not equally active or its uptake varies in different apicomplexan parasites (Clastre et al. 2007).

Thus far, all genes related to the MEP pathway have been identified in the $P$. falciparum genome, but only three genes that encode the enzymes DOXP synthase, DOXP reductoisomerase and 2-C-methyl-D-erythritol2,4-cyclodiphosphate synthase have been functionally characterised. Due to their absence in human cells, enzymes from the MEP pathway are excellent molecular targets for the development of new antimalarial drugs. Field trials in humans have also demonstrated the effectiveness of fosmidomycin in the treatment of human malarial infections (Borrmann et al. 2005, 2006). Recent clinical studies showed that fosmidomycin was effective and well tolerated in the treatment of patients with acute uncomplicated P. falciparum malaria but, unfortunately, resulted in an unacceptably high rate of recrudescence (Wiesner et al. 2002).

Biosynthesis of isoprenoids in P. falciparum - The first reports demonstrating the biosynthesis of isoprenoids in Plasmodium were published by Rietz et al. (1967) and Skelton et al. (1969), showing the occurrence of ubiquinones- 8 and 9 in Plasmodium lophurae and the identification of ubiquinone- 8 biosynthesised by P. knowlesi, Plasmodium cynomolgi, and Plasmodium berghei. Afterwards, Mbaya et al. (1990) showed that schizont extracts of $P$. falciparum biosynthesised isoprenoid until the farnesyl pyrophosphate step upon incubation with $\left[{ }^{14} \mathrm{C}\right]$ mevalonate. Using $\left[{ }^{[4} \mathrm{C}\right]$ acetate, they also demonstrated that the isoprenoid metabolism appeared to be stage-dependent, which was shown by the increase in radiolabelled farnesyl pyrophosphate at the beginning of the schizogonic phase.

Several glycoconjugates, biosynthesised by the intraerythrocytic stages of $P$. falciparum, use dolichol and its phosphorylated derivatives as carrier lipids. Anchors and N-linked glycoproteins require dolichyl phosphate and dolichyl pyrophosphate as carriers of different monosaccharide constituents (Schwarz \& Datema 1982). Kimura et al. (1996) demonstrated the effect of N-linked glycoproteins on differentiation of intraerythrocytic stages of $P$. falciparum. Walter (1986) demonstrated the presence of dolichol kinase, a rate-limiting enzyme for the supply of dolichyl pyrophosphate, in P. falciparum. Many eukaryotic cells, such as yeast and a number of mammalian cells, are unable to incorporate more complex isoprenoid precursors such as $\left[{ }^{3} \mathrm{H}\right] \mathrm{FPP}$ and $\left[{ }^{3} \mathrm{H}\right]$ GGPP. In contrast, intraerythrocytic forms of $P$. falciparum easily metabolise these compounds when they are added to the culture medium, permitting the subsequent identification of higher isoprenoids. Accordingly, Couto et al. (1999) identified dolichol, dolichyl phosphate and dolichyl pyrophosphate of 55 and 60 carbons (11/12 isoprenic units) by metabolic labelling of parasites with $\left[{ }^{3} \mathrm{H}\right] \mathrm{FPP}$ and $\left[{ }^{3} \mathrm{H}\right] \mathrm{GGPP}$ in different intraerythrocytic stages of P. falciparum. This study was the first dem- 
onstration of short-chain dolichols in the phylum Apicomplexa. Despite the fact that few reports exist on the characterisation of dolichols in protozoans, the presence of short-chain isoprenoid species seems to be a common feature. Dolichols of 13 isoprene units in Trypanosoma cruzi (Parodi \& Quesada-Allue 1982), of 11 isoprene units in Crithidia fasciculata (Quesada-Allue \& Parodi 1983) and of 11 and 12 isoprene units in Trypanosoma brucei (Low et al. 1991) have been reported.

The biosynthetic pathways for cholesterol, dolichol and ubiquinones share the same initial steps. Using $\left[1-{ }^{14} \mathrm{C}\right]$ acetate and ${ }^{3} \mathrm{H}_{2} \mathrm{O}$ as labelling precursors, Vial et al. (1984) showed that cholesterol synthesis in P. falciparum was almost undetectable, in accordance with very low levels of measurable HMG-CoA reductase activity.

In $P$. falciparum, the biosynthesis of ubiquinone or coenzyme Q involves two major steps: synthesis of the benzoquinone by the shikimate pathway and synthesis of the isoprene side chain by the MEP pathway. The biosynthesis and regulation of coenzyme Q was also studied in protozoans. T. brucei and Leishmania major synthesise the polyprenyl side of ubiquinone via the mevalonate pathway (Low et al. 1991, Ranganathan \& Mukkada 1995). Coenzyme Q8 and coenzyme Q9 were detected in $P$. falciparum using $\left[{ }^{14} \mathrm{C}\right] \mathrm{PHBA}$ to label the benzoquinone ring in parasite-infected blood from Aotus trivirgatus monkeys (Schnell et al. 1971). de Macedo et al. (2002) demonstrated that P. falciparum has an active isoprenoid pathway for the biosynthesis of the isoprenic chain of coenzyme Q. Additionally, $P$. falciparum is able to synthesise different homologues of this molecule depending on the given intermediate. When labelling was performed with $\left[{ }^{3} \mathrm{H}\right] \mathrm{FPP}$, coenzyme $\mathrm{Q}$ with an isoprenic chain of 40 carbons $\left(\mathrm{Q}_{8}\right)$ was detected, whereas labelling with $\left[{ }^{3} \mathrm{H}\right] \mathrm{GGPP}$ resulted in $\mathrm{Q}_{9}(45$ carbons) moieties. These authors also demonstrated that nerolidol treatment of $P$. falciparum parasites results in a reduced ability to synthesise CoQ and inhibits $P$. falciparum growth in vitro. Rodrigues Goulart et al. (2004) demonstrated that terpenes (farnesol, nerolidol and linalool) exert an inhibitory effect on the biosynthesis of the isoprenic side chain of the benzoquinone ring of

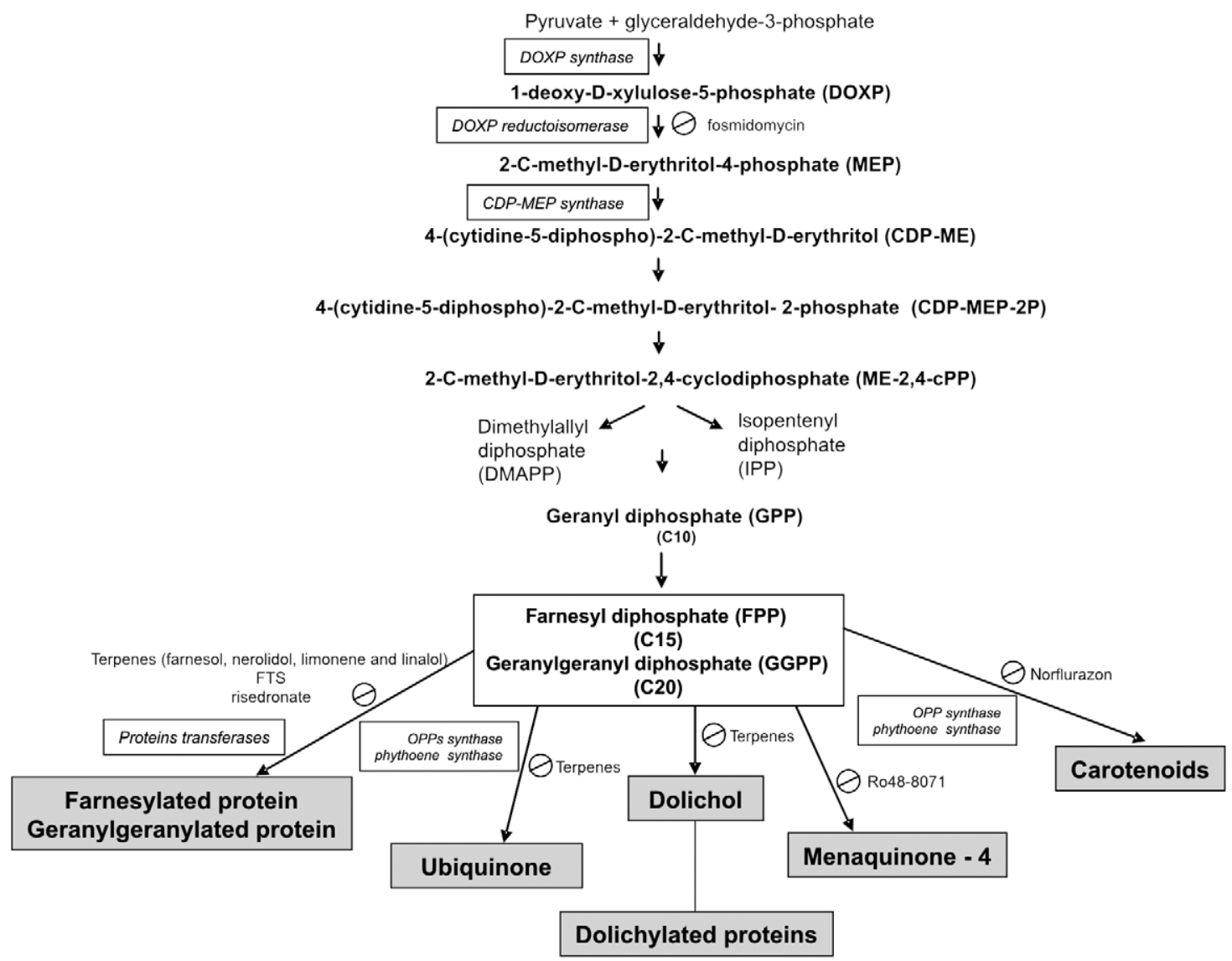

Isoprenoids biosynthesised by Plasmodium falciparum. IPP and DMAPP are biosynthesised by MEP. Steps that are engineered to improve isoprenoid compound production as described in the text are highlighted. The enzymes of this pathway that were characterised in P. falciparum are represented in white boxes and the corresponding inhibitors are in circles. In subsequent steps, IPP and DMAPP are utilised by prenyltransferases to produce a variety of linear allylic prenyl diphosphates of increasing size. GPP C10, FPP C15 and GGPP C20 are intermediates for the synthesis of the wide range of end products derived from the isoprenoid pathway. The shaded boxes indicate the isoprenics compounds currently characterised in P. falciparum by our group. The inhibitor of each isoprenic product is indicated in circles. In the white box, the bi-functional enzyme octaprenyl pyrophosphate synthase (OPPs)/phythoene synthase (PfB0130w) is represented. 
ubiquinones in the schizont stages. Also, these authors showed that all of these terpenes inhibited dolichol biosynthesis in trophozoite and schizont stages when $\left[{ }^{3} \mathrm{H}\right]$ FPP was used as a precursor (Figure).

Octaprenyl pyrophosphate synthase (OPPs) belongs to a prenyl transferase family, which catalyses the condensation reactions of FPP with five molecules of IPP to produce C40 OPP (Guo et al. 2004). OPP enzymes are responsible for the biosynthesis of side chains attached to ubiquinones in E. coli (Okada et al. 1996). Significant differences occur in the length of the isoprenic side chains of ubiquinones from different organisms, suggesting that specific prenyltransferases are involved in the synthesis of these side chains. For example, the sizes of the ubiquinone side chain are C30 in Saccharomyces cerevisiae, C45 in rats and C50 in humans, and these are synthesized by hexaprenyl pyrophosphate synthase, solanesyl pyrophosphate synthase and decaprenyl pyrophosphate synthase respectively (Ashby \& Edwards 1990, Teclebrhan et al. 1993). In P. falciparum, the isoprenic side chains of ubiquinone contain eight or nine isoprenic units, unlike humans, which contain 10 isoprenic units. These length differences of the isoprenoid side-chain compounds encountered in humans and the malaria parasite $P$. falciparum could possibly be exploited as drug targets (de Macedo et al. 2002).

Tonhosolo et al. (2005) demonstrated the existence of OPPs activity in P. falciparum, and the recombinant protein showed an OPP activity producing polyisoprenoids with eight isoprenic units from FPP and IPP as substrate. The transcription of PfOPPs was found to occur in the ring and trophozoite stages, while the polypeptide was mainly found in the schizont stages. These authors also showed that the recombinant enzyme could be competitively inhibited in the presence of the terpene nerolidol, which has a chemical structure that resembles the substrate FPP. These data suggest that nerolidol inhibits the biosynthesis of dolichol, thereby supporting earlier conclusions from de Macedo et al. (2002). Considering the differences in the length of isoprenic side chains in $P$. falciparum and humans, nerolidol could be exploited as a potential drug in malaria (Figure).

Our group has previously demonstrated that intraerythrocytic stages of $P$. falciparum biosynthesise certain unknown polyisoprenic compounds when $\left[{ }^{3} \mathrm{H}\right] \mathrm{GGPP}$ was used as a metabolic precursor (Couto et al. 1999). Taking into account that plant and algae plastids are sites for polyisoprenoid synthesis including carotenes, we investigated the possibility that $P$. falciparum was also able to produce carotenoids because carotenoids have GGPP as a precursor in other organisms.

The chemical characteristics and physical properties of carotenoids are responsible for their abilities to absorb light, scavenge free radicals and act as antioxidants, which are essential during photosynthesis. Tonhosolo et al. (2009) showed for the first time that the biosynthesis of carotenoids is functionally active in the intraerythrocytic stages of $P$. falciparum, representing another "plant-like" pathway present in these parasites. In this work, we detected that the full-length version of the previously de- scribed PfOPPs also exerted phytoene synthase activity. Accordingly, norflurazon, a well-known bleaching herbicide that inhibits carotenoid biosynthesis in higher plants and microalgae, inhibited in vitro growth of $P$. falciparum. This inhibition could be partially reversed by the addition of lycopene, a downstream product in the carotenoid pathway. The function of carotenoid in the malaria parasite is unknown. However, in T. gondii, Nagamune et al. (2008) demonstrated the biosynthesis of phytohormone abscisic acid, a final product of the biosynthesis of carotenoid, which controls calcium signalling within the apicomplexan parasite. Because carotenoid biosynthesis is absent in humans, this pathway might also be exploited as a new target for antimalarial drugs.

Vitamins are essential components of the human diet. By contrast, the malaria parasite P. falciparum and related apicomplexan parasites synthesise certain vitamins de novo, either completely or in part, highlighting the parasite's distinct requirements for nutrients and growth factors. Furthermore, the lack of these pathways in the mammalian host implies that inhibition of the parasite pathways might be exploitable for the design of new antimalarials. The MEP and shikimate pathways supply the precursors for biosynthesis of vitamin K2 or MQ in bacteria and phylloquinone in plants, algae and cyanobacteria. In P. falciparum, Tonhosolo et al. (2010) showed that the intraerythrocytic stages have an active pathway for the biosynthesis of MQ-4 and demonstrated that MQ could replace the physiological function of ubiquinone under anaerobic conditions. Many respiratory enzymes from $E$. coli can use MQ and ubiquinone as substrates depending on the oxygen supply in the environment, whereas mammals have only ubiquinone. $P$. falciparum can be regarded as microaerophilic during its asexual intraerythrocytic life cycle. Tonhosolo et al. (2010) showed that $P$. falciparum can change the content of the quinone pools depending on the aeration condition. Additionally, they showed that the mycobacterial inhibitor of MQ synthesis (Ro48-8071) suppressed MQ biosynthesis and parasite growth (Figure).

Post-translational modification of proteins with isoprenoids was first recognised as a general phenomenon in 1984 (Schmidt et al. 1984). The isoprenyl group is bound post-translationally to cysteine residues at the Cterminus of proteins through a thioether bond. Studies have shown that FPP (15 carbons) and GGPP (20 carbons) are the most common isoprenoids attached to proteins. Several of the proteins that undergo these modifications have been identified and many participate in important cell regulatory functions, particularly signal transduction pathways (Zhang \& Casey 1996). Protein prenylation is a general phenomenon in eukaryotic cells and has been described for several protozoan parasites (Lujan et al. 1995, Field et al. 1996, Shen et al. 1996, Ibrahim et al. 2001), including P. falciparum (Chakrabarti et al. 2002).

Families of Rab G-protein and Ras-related proteins have been characterised in P. falciparum (de Castro et al. 1996, Jambou et al. 1996) and Chakrabarti et al. $1998,2002)$ reported the identification of protein farnesyl transferase (PFT) and protein geranylgeranyl 
transferase-I activities in all stages of intraerythrocytic $P$. falciparum. Prenylation might occur in multiple compartments, but none of the P. falciparum prenyl transferases possess apicoplast-targeting signals and prenyl transferase activity has been detected only in cytosolic fractions. Additionally, peptidomimetics and prenyl analogues could inhibit PFT purified from parasites and malaria parasite growth. The presence of isoprenylated proteins has been demonstrated by metabolic labelling in T. gondii (Ibrahim et al. 2001).

Moura et al. (2001) characterised proteins with isoprenic groups by metabolic labelling with $\left[{ }^{3} \mathrm{H}\right] \mathrm{FPP}$ and $\left.{ }^{3} \mathrm{H}\right]$ GGPP. In the same work, treatment of parasites with limonene, an inhibitor of prenyl transferase, inhibited parasite growth by delaying maturation from ring to trophozoite stages and decreased the incorporation of the isoprenic group in proteins.

Later, Rodrigues Goulart et al. (2004) demonstrated that terpenes (farnesol, nerolidol, limonene and linalool) and S-farnesylthiosalicylic acid led to a decrease in the amount of isoprenylated proteins in P. falciparum schizont stages. Recently, Jordão et al. (2011) characterised the antiplasmodial activity of risedronate in vitro and in vivo and demonstrated that risedronate inhibits the transfer of the farnesyl pyrophosphate group to parasite proteins coinciding with parasite growth inhibition in vitro. In vivo treatment with risedronate led to an $88.9 \%$ inhibition of the rodent parasite $P$. berghei in mice on the seventh day of treatment; however, no general increase in survival rates was achieved.

Another type of protein modification is the attachment of a dolichyl group to proteins. This type of modification is characterised by covalently and posttranslationally bound dolichyl groups to the C-terminal cysteine residues of proteins. The protein dolichylation was described in tumour cells and dolichylated proteins are possibly involved in cell cycle control (Hjertman et al. 1997). In P. falciparum, dolichylated proteins with 11 isoprenic units were found attached to 21 and $28 \mathrm{kDa}$ sized proteins. The purpose of dolichylation of proteins in P. falciparum is currently unknown. Because the dolichylated protein species appear predominantly during the replication phase of the parasite (schizogony) (D'Alexandri et al. 2006), one may speculate that its involvement in cell cycle control is similar to that in tumour cells (Hjertman et al. 1997).

Final comments - Despite all of the recent progress in the understanding of the synthesis and the detection of unexpected metabolic intermediates such as phytoene, many questions still remain unanswered. For example, what purpose do carotenes have in the life cycle of Plasmodium? What are proteins modified with isoprenic residues and at which point in the metabolism of Plasmodium do they exert their function? The answers for these questions may reveal not only novel aspects of this evolutionarily special parasite group but also novel points of chemotherapeutic intervention.

\section{ACKNOWLEDGEMENTS}

To Dr Gerhard Wunderlich, for critical reading of manuscript.

\section{REFERENCES}

Alberts, Chen J, Kuron G, Hunt V, Huff J, Hoffman C, Rothrock J, Lopez M, Joshua H, Harris E, Patchett A, Monaghan R, Currie S, Stapley E, Albers-Schonberg G, Hensens O, Hirshfield J, Hoogsteen K, Liesch J, Springer J 1980. Mevinolin: a highly potent competitive inhibitor of hydroxymethylglutaryl-coenzyme A reductase and a cholesterol-lowering agent. Proc Natl Acad Sci USA 77: 3957-3961.

Ashby MN, Edwards PA 1990. Elucidation of the deficiency in two yeast coenzyme Q mutants. Characterization of the structural gene encoding hexaprenyl pyrophosphate synthetase. $J$ Biol Chem 265: 13157-13164.

Bailey AM, Mahapatra S, Brennan PJ, Crick DC 2002. Identification, cloning, purification and enzymatic characterization of Mycobacterium tuberculosis 1-deoxy-D-xylulose 5-phosphate synthase. Glycobiology 12: 813-820.

Block K 1958. On the mechanism of squalene biogenesis from mevalonic acid. Proceedings of the IV International Congress of Biochemistry, Pergamon Press, VIenna, London, p. 20-22.

Borrmann S, Adegnika AA, Moussavou F, Oyakhirome S, Esser G, Matsiegui PB, Ramharter M, Lundgren I, Kombila M, Issifou S, Hutchinson D, Wiesner J, Jomaa H, Kremsner PG 2005. Shortcourse regimens of artesunate-fosmidomycin in treatment of uncomplicated Plasmodium falciparum malaria. Antimicrob Agents Chemother 49: 3749-3754.

Borrmann S, Lundgren I, Oyakhirome S, Impouma B, Matsiegui PB, Adegnika AA, Issifou S, Kun JF, Hutchinson D, Wiesner J, Jomaa H, Kremsner PG 2006. Fosmidomycin plus clindamycin for treatment of pediatric patients aged 1 to 14 years with Plasmodium falciparum malaria. Antimicrob Agents Chemother 50: 2713-2718.

Burda P, Aebi M 1999. The dolichol pathway of N-linked glycosylation. Biochim Biophys Acta 1426: 239-257.

Cassera MB, Gozzo FC, D’Alexandri FL, Merino EF, del Portillo HA, Peres VJ, Almeida IC, Eberlin MN, Wunderlich G, Wiesner J, Jomaa H, Kimura EA, Katzin AM 2004. The methylerythritol phosphate pathway is functionally active in all intraerythrocytic stages of Plasmodium falciparum. J Biol Chem 279: 51749-51759.

Cassera MB, Merino EF, Peres VJ, Kimura EA, Wunderlich G, Katzin AM 2007. Effect of fosmidomycin on metabolic and transcript profiles of the methylerythritol phosphate pathway in Plasmodium falciparum. Mem Inst Oswaldo Cruz 102: 377-383.

Chakrabarti D, Azam T, DelVecchio C, Qiu L, Park YI, Allen CM 1998. Protein prenyl transferase activities of Plasmodium falciparum. Mol Biochem Parasitol 94: 175-184.

Chakrabarti D, Da Silva T, Barger J, Paquette S, Patel H, Patterson S, Allen CM 2002. Protein farnesyltransferase and protein prenylation in Plasmodium falciparum. J Biol Chem 277: 42066-42073.

Clastre M, Goubard A, Prel A, Mincheva Z, Viaud-Massuart MC, Bout D, Rideau M, Velge-Roussel F, Laurent F 2007. The methylerythritol phosphate pathway for isoprenoid biosynthesis in coccidia: presence and sensitivity to fosmidomycin. Exp Parasitol 116: 375-384.

Connolly JD, Hill RA 1992. Dictionary of terpenoids, Chapman \& Hall, New York, 2156 pp.

Couto AS, Kimura EA, Peres VJ, Uhrig ML, Katzin AM 1999. Active isoprenoid pathway in the intra-erythrocytic stages of Plasmodium falciparum: presence of dolichols of 11 and 12 isoprene units. Biochem J 341: 629-637.

Cox-Singh J, Singh B 2008. Knowlesi malaria: newly emergent and of public health importance? Trends Parasitol 24: 406-410.

Cvejic JH, Rohmer M 2000. CO2 as main carbon source for isoprenoid biosynthesis via the mevalonate-independent methylerythritol 4-phosphate route in the marine diatoms Phaeodactylum tricornutum and Nitzschia ovalis. Phytochemistry 53: 21-28. 
D’Alexandri FL, Kimura EA, Peres VJ, Katzin AM 2006. Protein dolichylation in Plasmodium falciparum. FEBS Lett 580: 6343-6348.

de Castro FA, Ward GE, Jambou R, Attal G, Mayau V, Jaureguiberry G, Braun-Breton C, Chakrabarti D, Langsley G 1996. Identification of a family of Rab G-proteins in Plasmodium falciparum and a detailed characterisation of pfrab6. Mol Biochem Parasitol 80: 77-88.

de Macedo CS, Uhrig ML, Kimura EA, Katzin AM 2002. Characterization of the isoprenoid chain of coenzyme Q in Plasmodium falciparum. FEMS Microbiol Lett 207: 13-20.

Disch A, Schwender J, Muller C, Lichtenthaler HK, Rohmer M 1998. Distribution of the mevalonate and glyceraldehyde phosphate/ pyruvate pathways for isoprenoid biosynthesis in unicellular algae and the cyanobacterium Synechocystis PCC 6714. Biochem $J$ 333: $381-388$

Field H, Blench I, Croft S, Field MC 1996. Characterisation of protein isoprenylation in procyclic form Trypanosoma brucei. Mol Biochem Parasitol 82: 67-80.

Funes S, Davidson E, Reyes-Prieto A, Magallon S, Herion P, King MP, Gonzalez-Halphen D 2002. A green algal apicoplast ancestor. Science 298: 2155.

Gardner MJ, Hall N, Fung E, White O, Berriman M, Hyman RW, Carlton JM, Pain A, Nelson KE, Bowman S, Paulsen IT, James K, Eisen JA, Rutherford K, Salzberg SL, Craig A, Kyes S, Chan MS, Nene V, Shallom SJ, Suh B, Peterson J, Angiuoli S, Pertea M, Allen J, Selengut J, Haft D, Mather MW, Vaidya AB, Martin DM, Fairlamb AH, Fraunholz MJ, Roos DS, Ralph SA, McFadden GI, Cummings LM, Subramanian GM, Mungall C, Venter JC, Carucci DJ, Hoffman SL, Newbold C, Davis RW, Fraser CM, Barrell B 2002. Genome sequence of the human malaria parasite Plasmodium falciparum. Nature 419: 498-511.

Goldstein JL, Brown MS 1990. Regulation of the mevalonate pathway. Nature 343: 425-430.

Grellier P, Valentin A, Millerioux V, Schrevel J, Rigomier D 1994. 3-hydroxy-3-methylglutaryl coenzyme A reductase inhibitors lovastatin and simvastatin inhibit in vitro development of Plasmodium falciparum and Babesia divergens in human erythrocytes. Antimicrob Agents Chemother 38: 1144-1148.

Guiguemde WA, Shelat AA, Bouck D, Duffy S, Crowther GJ, Davis PH, Smithson DC, Connelly M, Clark J, Zhu F, Jimenez-Diaz MB, Martinez MS, Wilson EB, Tripathi AK, Gut J, Sharlow ER, Bathurst I, El Mazouni F, Fowble JW, Forquer I, McGinley PL, Castro S, Angulo-Barturen I, Ferrer S, Rosenthal PJ, Derisi JL, Sullivan DJ, Lazo JS, Roos DS, Riscoe MK, Phillips MA, Rathod PK, Van Voorhis WC, Avery VM, Guy RK 2010. Chemical genetics of Plasmodium falciparum. Nature 465: 311-315.

Guo RT, Kuo CJ, Chou CC, Ko TP, Shr HL, Liang PH, Wang AH 2004. Crystal structure of octaprenyl pyrophosphate synthase from hyperthermophilic Thermotoga maritima and mechanism of product chain length determination. J Biol Chem 279: 4903-4912.

Hjertman M, Wejde J, Dricu A, Carlberg M, Griffiths WJ, Sjovall J, Larsson O 1997. Evidence for protein dolichylation. FEBS Lett 416: $235-238$.

Ibrahim M, Azzouz N, Gerold P, Schwarz RT 2001. Identification and characterisation of Toxoplasma gondii protein farnesyltransferase. Int J Parasitol 31: 1489-1497.

Jambou R, Zahraoui A, Olofsson B, Tavitian A, Jaureguiberry G 1996. Small GTP-binding proteins in Plasmodium falciparum. Biol Cell 88: 113-121.

Jomaa H, Wiesner J, Sanderbrand S, Altincicek B, Weidemeyer C, Hintz M, Turbachova I, Eberl M, Zeidler J, Lichtenthaler HK, Soldati D, Beck E 1999. Inhibitors of the nonmevalonate pathway of isoprenoid biosynthesis as antimalarial drugs. Science 285: 1573-1576.
Jordão FM, Saito AY, Miguel DC, Peres VD, Kimura EA, Katzin AM 2011. In vitro and in vivo antiplasmodial activity of risedronate and its interference with protein prenylation in Plasmodium falciparum. Antimicrob Agents Chemother 55: 2026-2031.

Kimura EA, Couto AS, Peres VJ, Casal OL, Katzin AM 1996. N-linked glycoproteins are related to schizogony of the intraerythrocytic stage in Plasmodium falciparum. J Biol Chem 271: 14452-14461.

Kuzuyama T, Shimizu T, Takahashi S, Seto H 1998. Fosmidomycin, a specific inhibitor of 1-deoxy-D-xylulose-5-phosphate reductoisomerase in the nonmevalonate pathway for terpenoid biosynthesis. Tetrahedron Lett 39: 7913-7916.

Lichtenthaler HK 2000. Non-mevalonate isoprenoid biosynthesis: enzymes, genes and inhibitors. Biochem Soc Trans 28: 785-789.

Lim L, McFadden GI 2010. The evolution, metabolism and functions of the apicoplast. Philos Trans R Soc Lond B Biol Sci 365: 749-763.

Lois LM, Campos N, Putra SR, Danielsen K, Rohmer M, Boronat A 1998. Cloning and characterization of a gene from Escherichia coli encoding a transketolase-like enzyme that catalyzes the synthesis of D-1-deoxyxylulose 5-phosphate, a common precursor for isoprenoid, thiamin, and pyridoxol biosynthesis. Proc Natl Acad Sci USA 95: 2105-2110.

Lombard J, Moreira D 2011. Origins and early evolution of the mevalonate pathway of isoprenoid biosynthesis in the three domains of life. Mol Biol Evol 28: 87-99.

Low P, Dallner G, Mayor S, Cohen S, Chait BT, Menon AK 1991. The mevalonate pathway in the bloodstream form of Trypanosoma brucei. Identification of dolichols containing 11 and 12 isoprene residues. J Biol Chem 266: 19250-19257.

Lujan HD, Mowatt MR, Chen GZ, Nash TE 1995. Isoprenylation of proteins in the protozoan Giardia lamblia. Mol Biochem Parasitol 72: 121-127.

Lynen F 1958. Ciba Foundation Symposium o Bio-synthesis of Terpenes and Sterols, GE Wolstenholrne, CM O'Connor (eds.), J and A Churchill, London, 95 pp.

Mbaya B, Rigomier D, Edorh GG, Karst F, Schrevel J 1990. Isoprenoid metabolism in Plasmodium falciparum during the intraerythrocytic phase of malaria. Biochem Biophys Res Commun 173: 849-854.

McFadden GI, Reith ME, Munholland J, Lang-Unnasch N 1996. Plastid in human parasites. Nature 381: 482

Moore RB, Obornik M, Janouskovec J, Chrudimsky T, Vancova M, Green DH, Wright SW, Davies NW, Bolch CJ, Heimann K, Slapeta J, Hoegh-Guldberg O, Logsdon JM, Carter DA 2008. A photosynthetic alveolate closely related to apicomplexan parasites. Nature 451: 959-963.

Moura IC, Wunderlich G, Uhrig ML, Couto AS, Peres VJ, Katzin AM, Kimura EA 2001. Limonene arrests parasite development and inhibits isoprenylation of proteins in Plasmodium falciparum. Antimicrob Agents Chemother 45: 2553-2558.

Nagamune K, Hicks LM, Fux B, Brossier F, Chini EN, Sibley LD 2008. Abscisic acid controls calcium-dependent egress and development in Toxoplasma gondii. Nature 451: 207-210.

Okada K, Suzuki K, Kamiya Y, Zhu X, Fujisaki S, Nishimura Y, Nishino T, Nakagawa T, Kawamukai M, Matsuda H 1996. Polyprenyl diphosphate synthase essentially defines the length of the side chain of ubiquinone. Biochim Biophys Acta 1302: 217-223.

Parodi AJ, Quesada-Allue LA 1982. Protein glycosylation in Trypanosoma cruzi. I. Characterization of dolichol-bound monosaccharides and oligosaccharides synthesized "in vivo". J Biol Chem 257: 7637-7640.

Quesada-Allue LA, Parodi AJ 1983. Novel mannose carrier in the trypanosomatid Crithidia fasciculata behaving as a short alphasaturated polyprenyl phosphate. Biochem J 212: 123-128. 
Ralph SA, van Dooren GG, Waller RF, Crawford MJ, Fraunholz MJ, Foth BJ, Tonkin CJ, Roos DS, McFadden GI 2004. Tropical infectious diseases: metabolic maps and functions of the Plasmodium falciparum apicoplast. Nat Rev Microbiol 2: 203-216.

Ranganathan G, Mukkada AJ 1995. Ubiquinone biosynthesis in Leishmania major promastigotes. Int J Parasitol 25: 279-284.

Ridley RG 2002. Medical need, scientific opportunity and the drive for antimalarial drugs. Nature 415: 686-693.

Rietz PJ, Skelton FS, Folkers K 1967. Occurrence of ubiquinones-8 and -9 in Plasmodium lophurae. Int Z Vitaminforsch 37: 405-411.

Rodrigues Goulart H, Kimura EA, Peres VJ, Couto AS, Aquino Duarte FA, Katzin AM 2004. Terpenes arrest parasite development and inhibit biosynthesis of isoprenoids in Plasmodium falciparum. Antimicrob Agents Chemother 48: 2502-2509.

Rohdich F, Eisenreich W, Wungsintaweekul J, Hecht S, Schuhr CA, Bacher A 2001. Biosynthesis of terpenoids. 2C-methyl-D-erythritol 2,4-cyclodiphosphate synthase (IspF) from Plasmodium falciparum. Eur J Biochem 268: 3190-3197.

Rohmer M 1999. The discovery of a mevalonate-independent pathway for isoprenoid biosynthesis in bacteria, algae and higher plants. Nat Prod Rep 16: 565-574.

Rohmer M, Knani M, Simonin P, Sutter B, Sahm H 1993. Isoprenoid biosynthesis in bacteria: a novel pathway for the early steps leading to isopentenyl diphosphate. Biochem J 295: 517-524.

Schmidt RA, Schneider CJ, Glomset JA 1984. Evidence for posttranslational incorporation of a product of mevalonic acid into Swiss 3T3 cell proteins. J Biol Chem 259: 10175-10180.

Schnell JV, Siddiqui WA, Geiman QM 1971. Biosynthesis of coenzymes $Q$ by malarial parasites. 2. Coenzyme $Q$ synthesis in blood cultures of monkeys infected with malarial parasites (Plasmodium falciparum and P. knowlesi). J Med Chem 14: 1026-1029.

Schwarz RT, Datema R 1982. The lipid pathway of protein glycosylation and its inhibitors: the biological significance of protein-bound carbohydrates. Adv Carbohydr Chem Biochem 40: 287-379.

Shen PS, Sanford JC, Samuelson J 1996. Entamoeba histolytica: isoprenylation of p21ras and p21rap in vitro. Exp Parasitol 82: 65-68.

Skelton FS, Lunan KD, Folkers K, Schnell JV, Siddiqui WA, Geiman QM 1969. Biosynthesis of ubiquinones by malarial parasites. I. Isolation of [14C]ubiquinones from cultures of rhesus monkey blood infected with Plasmodium knowlesi. Biochemistry 8: 1284-1287.

Snow RW, Guerra CA, Noor AM, Myint HY, Hay SI 2005. The global distribution of clinical episodes of Plasmodium falciparum malaria. Nature 434: 214-217.

Spiro RG 2002. Protein glycosylation: nature, distribution, enzymatic formation and disease implications of glycopeptide bonds. Glycobiology 12: 43R-56R.

Sprenger GA, Schorken U, Wiegert T, Grolle S, de Graaf AA, Taylor SV, Begley TP, Bringer-Meyer S, Sahm H 1997. Identification of a thiamin-dependent synthase in Escherichia coli required for the formation of the 1-deoxy-D-xylulose 5-phosphate precursor to isoprenoids, thiamin, and pyridoxol. Proc Natl Acad Sci USA 94: 12857-12862.
Spurgeon SL, Porter JW 1981. Biosynthesis of isoprenoid compounds, vol. 1, Wiley, New York, p. 1-46.

Sullivan M, Li J, Kumar S, Rogers MJ, McCutchan TF 2000. Effects of interruption of apicoplast function on malaria infection, development and transmission. Mol Biochem Parasitol 109: 17-23.

Teclebrhan H, Olsson J, Swiezewska E, Dallner G 1993. Biosynthesis of the side chain of ubiquinone:trans-prenyltransferase in rat liver microsomes. J Biol Chem 268: 23081-23086.

Tonhosolo R, D’Alexandri FL, de Rosso VV, Gazarini ML, Matsumura MY, Peres VJ, Merino EF, Carlton JM, Wunderlich G, Mercadante AZ, Kimura EA, Katzin AM 2009. Carotenoid biosynthesis in intraerythrocytic stages of Plasmodium falciparum. J Biol Chem 284: 9974-9985.

Tonhosolo R, D’Alexandri FL, Genta FA, Wunderlich G, Gozzo FC, Eberlin MN, Peres VJ, Kimura EA, Katzin AM 2005. Identification, molecular cloning and functional characterization of an octaprenyl pyrophosphate synthase in intra-erythrocytic stages of Plasmodium falciparum. Biochem J 392: 117-126.

Tonhosolo R, Gabriel HB, Matsumura MY, Cabral FJ, Yamamoto MM, D’Alexandri FL, Sussmann RA, Belmonte R, Peres VJ, Crick DC, Wunderlich G, Kimura EA, Katzin AM 2010. Intraerythrocytic stages of Plasmodium falciparum biosynthesize menaquinone. FEBS Lett 584: 4761-4768.

Umeda T, Tanaka N, Kusakabe Y, Nakanishi M, Kitade Y, Nakamura KT 2010. Crystallization and preliminary X-ray crystallographic study of 1-deoxy-D-xylulose 5-phosphate reductoisomerase from Plasmodium falciparum. Acta Crystallogr Sect F Struct Biol Cryst Commun 66: 330-332.

Vial HJ, Philippot JR, Wallach DF 1984. A reevaluation of the status of cholesterol in erythrocytes infected by Plasmodium knowlesi and P. falciparum. Mol Biochem Parasitol 13: 53-65.

Walter RD 1986. Plasmodium falciparum: inhibition of dolichol kinase by mefloquine. Exp Parasitol 62: 356-361.

Wang K, Ohnuma S 1999. Chain-length determination mechanism of isoprenyl diphosphate synthases and implications for molecular evolution. Trends Biochem Sci 24: 445-451.

WHO - World Health Organization 2010. World Malaria Report, WHO, Geneva, 238 pp.

Wiesner J, Henschker D, Hutchinson DB, Beck E, Jomaa H 2002. In vitro and in vivo synergy of fosmidomycin, a novel antimalarial drug, with clindamycin. Antimicrob Agents Chemother 46: 2889-2894.

Wiesner J, Hintz M, Altincicek B, Sanderbrand S, Weidemeyer C, Beck E, Jomaa H 2000. Plasmodium falciparum: detection of the deoxyxylulose 5-phosphate reductoisomerase activity. Exp Parasitol 96: 182-186.

Zhang B, Watts KM, Hodge D, Kemp LM, Hunstad DA, Hicks LM, Odom AR 2011. A second target of the antimalarial and antibacterial agent fosmidomycin revealed by cellular metabolic profiling. Biochemistry 50: 3570-3577.

Zhang FL, Casey PJ 1996. Protein prenylation: molecular mechanisms and functional consequences. Annu Rev Biochem 65: 241-269.

Zhang K, Rathod PK 2002. Divergent regulation of dihydrofolate reductase between malaria parasite and human host. Science 296: 545-547. 